J. Dairy Sci. 95:2819-2829

http://dx.doi.org/10.3168/jds.2011-4837

(C) American Dairy Science Association ${ }^{\circledR}, 2012$.

\title{
Proteolytic activation of proteose peptone component 3 by release of a C-terminal peptide with antibacterial properties
}

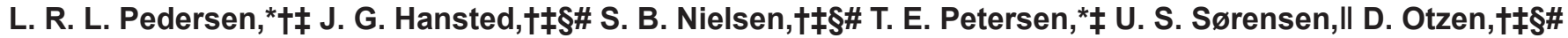 \\ and E. S. Sørensen ${ }^{\star} \dagger \ddagger^{1}$ \\ *Protein Chemistry Laboratory, \\ †Interdisciplinary Nanoscience Center (iNANO), \\ $\ddagger$ Department of Molecular Biology and Genetics, \\ §Protein Biophysics Group, \\ \#Center for Insoluble Protein Structures (inSPIN), and \\ IIDepartment of Biomedicine, Aarhus University, DK-8000 Aarhus, Denmark
}

\section{ABSTRACT}

The milk protein proteose peptone component 3 (PP3, also known as lactophorin) is a small phosphoglycoprotein, which is exclusively expressed in the lactating mammary gland. A 23-residue synthetic peptide (lactophoricin, Lpcin S), corresponding to the C-terminal amphipathic $\alpha$-helix of PP3, has previously been shown to permeabilize membranes and display antibacterial activity. Lactophorin readily undergoes proteolytic cleavage in milk and during dairy processing, and it has been suggested that PP3-derived peptides are part of milk's endogenous defense system against bacteria. Here, we report that a 26 -residue C-terminal peptide (Lpcin P) can be generated by trypsin proteolysis of PP3 and that structural and functional studies of Lpcin P indicate that the peptide has antibacterial properties. The Lpcin P showed $\alpha$-helical structure in both anionic and organic solvents, and the amount of $\alpha$-helical structure was increased in the presence of lipid vesicles. Oriented circular dichroism showed that Lpcin $\mathrm{P}$ oriented parallel to the membrane surface. However, the peptide permeabilized calcein-containing vesicles efficiently. Lpcin $\mathrm{P}$ displayed antibacterial activity against Streptococcus thermophilus, but not against Staphylococcus aureus and Escherichia coli. The PP3 full-length protein did not display the same properties, which could indicate that PP3 functions as a precursor protein that upon proteolysis, releases a bioactive antibacterial peptide.

Key words: antibacterial peptide, antimicrobial activity, lactophoricin, proteose peptone component 3

Received August 16, 2011.

Accepted January 29, 2012.

${ }^{1}$ Corresponding author: ess@mb.au.dk

\section{INTRODUCTION}

Milk is one of nature's great sources of bioactive proteins and peptides. This reflects the particular purposes to which milk is dedicated beyond nutrition in the first months of life. Milk components like lactoferrin and lactoperoxidase show a wide range of antimicrobial activities against bacteria, fungi, and viruses (Zimecki and Kruzel, 2007). Physiologically active peptides can be found encrypted in an inactive form within the sequence of the parent protein and can be released by, for example, gastrointestinal digestion and fermentation by lactic acid bacteria (Zimecki and Kruzel, 2007). Especially the whey fraction of milk represents a rich and heterogeneous source of antimicrobial peptides (AMP) and scientific and industrial interest is growing to exploit what was formerly considered a waste product (Expósito and Recio, 2006).

The whey protein proteose peptone component 3 (PP3, also known as lactophorin) has been isolated and characterized in the milk of several ruminants (Beg et al., 1987; Cantisani et al., 1990; Sørensen and Petersen, 1993a,b; Sørensen et al., 1997; Lister et al., 1998). Bovine PP3 is exclusively expressed in the lactating mammary gland (Groenen et al., 1995) and PP3 is not expressed in human milk or tissue (Sørensen et al., 1997; Rasmussen et al., 2002). However, a highly similar protein, glycosylation-dependent adhesion molecule 1 (GlyCAM-1), has been found in lymph nodes, the lung, cochlea, and mammary gland of mice and rats (Lasky et al., 1992; Dowbenko et al., 1993a,b; Kanoh et al., 1999) and in the ovine uterus (Spencer et al., 1999). Though the murine GLYCAM- 1 sequence is $56 \%$ identical to the bovine PP3 cDNA sequence (Groenen et al., 1995; Johnsen et al., 1995), the specific expression pattern of the proteins makes it unlikely that they are functional analogs and we, therefore, refer to the protein from milk as PP3 or lactophorin. 
Proteose peptone component 3 consists of 135 AA and contains at least 2 distinct domains: a largely negatively charged $\mathrm{N}$-terminal part and a C-terminal part, displaying a clear amphipathic character (Campagna et al., 1998; Bak et al., 2000). Proteose peptone component 3 is present in multimeric complexes in milk (Sørensen et al., 1997) and recently we reported that PP3 forms stable tetrameric complexes (Pedersen et al., 2012). Residues 98 to 135 have been shown to form an amphipathic membrane binding $\alpha$-helix, which is oriented in plane with the membrane surface when incorporated in planar phospholipid bilayers (Bak et al., 2000). A cationic synthetic peptide modeled after residues 113 to 135 [named lactophoricin (Lpcin, and in this article Lpcin S; Figure 1B) can also form voltage-dependent channels in planar lipid bilayers (Campagna et al., 2001). It has been suggested that Lpcin S may permeabilize the membranes in a manner described as the barrel-stave mechanism (Campagna et al., 2001), in which a bundle of peptides associate to form an ion channel (Sansom, 1991). An alternative permeabilization mechanism is the toroidal model, where accumulation of parallel-oriented AMP leads to a pore with continuities between inner and outer leaflet. Thereby, the aqueous channel is lined by both AMP and lipid head groups (Matsuzaki et al., 1996). In the carpet model, parallel-oriented AMP also accumulate and destabilize the lipid bilayer via a detergent-like effect, resulting in disintegration of the membrane and subsequent liposome or cell lysis (Oren and Shai, 1998). The channel-forming activities of Lpcin S prompted further studies, which showed that the peptide limited the growth of more bacterial species in dose-response fashion and even demonstrated bactericidal activity against Streptococcus thermophilus (Campagna et al., 2004).

The AA sequence of PP3 contains 4 cleavage sites for plasmin (Figure 1B) as well as several cleavage sites for trypsin and other proteases from the digestive system. In bovine milk, PP3 is known to be cleaved by plasmin, leaving a significant part of the PP3 content in milk as proteolytic peptides (Sørensen and Petersen, 1993a). The formation of these peptides in milk could potentially be a part of the endogenous defense system of milk against bacteria. If it is possible to generate peptides in a way resembling the physiological generation of AMP, the dairy industry may potentially be able to use PP3-derived peptides in regulating fermentation processes involving bacteria that are influenced by the presence such peptides, especially Strep. thermophilus.

Previous conformational and antibacterial studies of the synthetic Lpcin S encouraged us to investigate the peptides generated from native PP3 and examine whether they possess antibacterial effects. In vitro tryp- sin proteolysis of native PP3 generated a peptide covering the C-terminal 26 AA (residues 110-135, in this article called Lpcin $\mathbf{P}$ ). This gave us the opportunity to investigate the structural and functional features of a biologically generated peptide analogous to the previously studied synthetic peptide Lpcin S (Campagna et al., 1998; Campagna et al., 1999; Campagna et al., 2001; Campagna et al., 2004; Barzyk et al., 2009).

In the present study, we have analyzed the secondary structure of Lpcin P by circular dichroism (CD), followed by oriented CD (OCD), to determine how the peptide orients in lipid bilayers of either $100 \%$ electrically neutral lipids or a mixture of electrically neutral and negatively charged lipids. These model membranes mimic the membranes of animals and bacteria, respectively, as the outer leaflet (surface) of bacterial membranes is more negatively charged than the outer leaflet of animal membranes (Graham and Higgins, 1997). We found that Lpcin $\mathrm{P}$ showed a high degree of $\alpha$-helical structure in both buffered aqueous and membrane-like environments. The peptide remained on the surface of

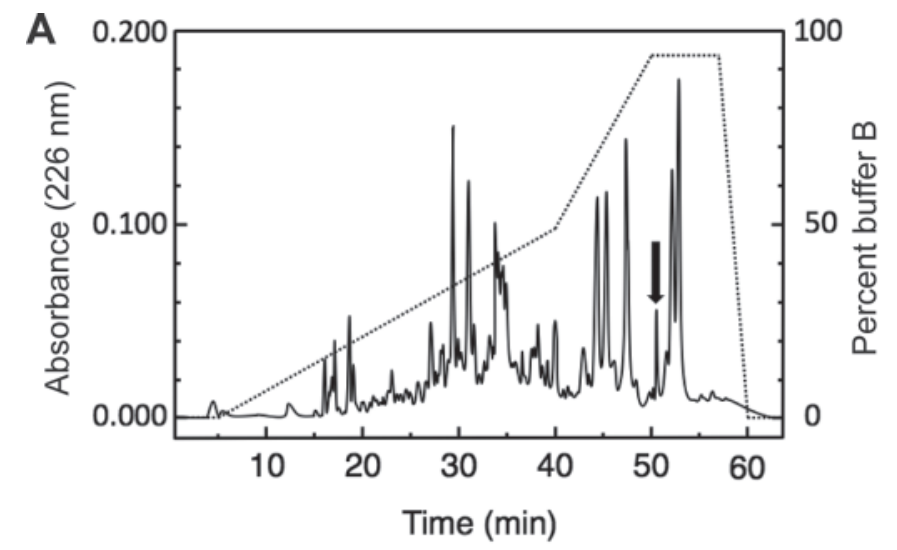

B

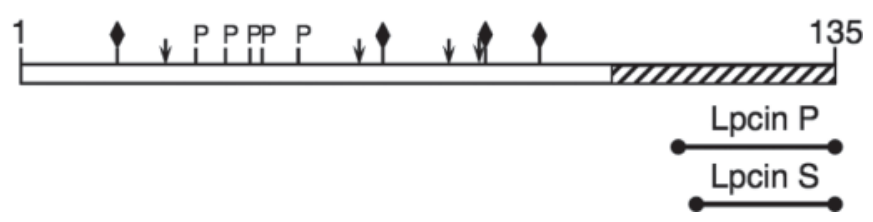

Figure 1. Purification of the peptide (Lpcin P) covering the C-terminal 26 AA (residues 110 to 135) generated by in vitro trypsin proteolysis of native proteose peptone component 3 (PP3). A) Reversephase HPLC elution profile of a trypsin digest of PP3. The proteolytic digest was separated on a Vydac C18 column with a gradient of $80 \%$ acetonitrile (buffer B) in $0.1 \%$ trifluoroacetic acid (buffer A) at $40^{\circ} \mathrm{C}$. Detection was at $226 \mathrm{~nm}$. The dashed line indicates the gradient and the peak containing Lpcin P is marked by the arrow. B) Schematic presentation of PP3, showing phosphorylation sites (P), glycosylation sites $(\bullet)$, and observed plasmin cleavage sites $(\downarrow$; Sørensen and Petersen, 1993a). The hatched area indicates the part constituting the potential amphipathic helix (Bak et al., 2000). The part of PP3 corresponding to the sequences of Lpcin P (26 residues) and lactophoricin [Lpcin S; 23 residues (residues 113-135)] is indicated. 
lipid bilayers in physiological buffer according to OCD. Moreover, it was able to permeabilize liposomes of both $100 \%$ electrically neutral lipids and liposomes of $20 \%$ negatively charged lipids. Finally, Lpcin P showed antibacterial activity against Strep. thermophilus, but not Escherichia coli and Staphylococcus aureus. The results demonstrate that a natural proteolytic degradation product of PP3 Lpcin P, may, to some degree, influence the growth of bacteria.

\section{MATERIALS AND METHODS}

\section{Materials}

The trypsin used was from Worthington Biochemical Corp. (Lakewood, NJ). The Vydac C18 column was from The Separations Group (Hesperia, CA). Acetonitrile $99.9 \%$ purity was from Sigma (St. Louis, MO) and trifluoroacetic acid (TFA) was of sequencer grade and from Rathburn Chemicals Ltd. (Walkerburn, Scotland). The synthetic Lpcin S was purchased from Caslo Laboratory ApS (Lyngby, Denmark). 1,2-Dioleoylphosphatidylcholine (DOPC) and 1,2-dioleoylphosphatidylglycerol (DOPG) were purchased in powder form from Avanti Polar Lipids Inc. (Alabaster, AL). Chloroform of $99 \%$ purity or higher and Tween-20 were from Sigma. Calcein disodium salt was purchased from Fluka Chemie GmbH (Buchs, Switzerland). The M17 agar and broth were from Becton, Dickinson and Co. (Le Pont-de-Claix, France). Blood agar plates were from SSI (Hillerød, Denmark). Todd Hewitt broth no. CM189 was from Oxoid Ltd. (Basingstoke, UK). Novicidin was a kind gift from Hans Henrik Kristensen, Novozymes A/S (Copenhagen, DK)

\section{Purification, Generation, and Characterization of Proteins and Peptides}

Full-length native PP3 was isolated from bovine milk as described by Sørensen and Petersen (1993b). Edman sequence analysis and SDS-PAGE showed that the purity was $>95 \%$. The $\mathrm{C}$-terminal peptide, Lpcin $\mathrm{P}$, was generated by proteolytic digestion of PP 3 with trypsin for $2 \mathrm{~h}$ in $0.1 \mathrm{~N} \mathrm{H}_{4} \mathrm{HCO}_{3}(\mathrm{pH} 8.0)$ at $37^{\circ} \mathrm{C}$. Trypsin was used in a $0.1 \%$ (wt/wt) enzyme:substrate ratio. Peptides generated from the digests were separated by reverse-phase HPLC on a Vydac C18 column $(4 \times$ $250 \mathrm{~mm}$ ) using a LKB-Pharmacia 2249 Gradient pump (Pharmacia LKB Biotech AB, Uppsala, Sweden). The column was operated at $40^{\circ} \mathrm{C}$ at a flow rate of 0.850 $\mathrm{mL} / \mathrm{min}$. The digest was separated in $0.1 \%$ TFA (buffer A) and $80 \%$ acetonitrile in $0.1 \%$ TFA (buffer B). The gradient was as follows (each step being linear): 0 to $5 \mathrm{~min}, 0 \% \mathrm{~B} ; 5$ to $40 \mathrm{~min}, 0$ to $50 \% \mathrm{~B} ; 40$ to 50 min, 50 to $95 \%$ B; 50 to $57 \mathrm{~min}, 95 \% \mathrm{~B}$; and 57 to 60 min, 95 to $0 \%$ B. Peptides were detected in the effluent by measuring the absorption at $226 \mathrm{~nm}$, using an UVicord SII detector (Pharmacia LKB Biotech AB). The identities and purities of Lpcin $\mathrm{P}$ and Lpcin $\mathrm{S}$ were verified by mass spectrometric, AA, and N-terminal sequence analysis. Mass spectrometric analyses of the peptides were performed using a Voyager DE-PRO matrix-assisted laser-desorption ionization-time-offlight (MALDI-TOF) mass spectrometer (Applied Biosystems, Carlsbad, CA), using methods essentially as described by Christensen et al. (2008). The theoretical peptide masses and sequence coverage were calculated using the GPMAW program (Lighthouse Data, Odense, Denmark). The N-terminal AA sequence analysis was carried out by automated Edman degradation on an Applied Biosystems Procise protein sequencing system. The Lpcin S was used without further purification.

\section{Preparation of Large Unilamellar Vesicles}

The large unilamellar vesicles (LUV) were prepared from stock solutions of lipids dissolved in chloroform. The lipid solutions were dried under a stream of $\mathrm{N}_{2}$ and for solution CD and OCD they were resuspended in 10 $\mathrm{m} M \mathrm{Na}_{2} \mathrm{HPO}_{4}$ (pH 7.4) by vortexing. The resuspended lipids were then sonicated for 5 min with cycles of $90 \%$ sonication on ice, $10 \%$ pause, and $50 \%$ intensity until the solutions were clear. Titanium flakes from the probe were removed by centrifugation at $20,800 \times g$ for $1 \mathrm{~min}$ at $25^{\circ} \mathrm{C}$. For calcein dye leakage experiments, the dried lipids were resuspended in $10 \mathrm{~m} M \mathrm{Na}_{2} \mathrm{HPO}_{4}(\mathrm{pH}$ 7.4) containing $70 \mathrm{mM}$ calcein sodium salt to a final lipid concentration of $5 \mathrm{~g} / \mathrm{L}(6.36 \mathrm{~m} M)$. The suspension was then subjected to 10 cycles of freezing in liquid nitrogen and thawed in a $40^{\circ} \mathrm{C}$ water bath, before extrusion through a $100-\mathrm{nm}$ polycarbonate membrane 13 times using a 1-mL Avanti polar lipids Mini-Extruder (Avanti Polar Lipids Inc., Alabaster, AL). Extruded calcein-loaded LUV were passed over a PD-10 desalting column (GE Healthcare, Uppsala, Sweden) to separate vesicles with entrapped calcein from free calcein. The fractions were tested by fluorescence measurements with and without Tween-20 to test for calcein release. The calcein vesicle containing fractions with the highest signal-to-background ratio were pooled and used in subsequent release experiments.

\section{Solution Circular Dichroism}

Solution CD experiments were carried out using a Jasco J-810 spectropolarimeter (Jasco Spectroscopic Co., Hachioji City, Japan) with a Jasco PTC-348W1 temperature control unit. Spectra were recorded from 
260 to $190 \mathrm{~nm}$ in continuous scanning mode with a response time of $1 \mathrm{~s}, 0.2-\mathrm{nm}$ steps, a bandwidth of 2 $\mathrm{nm}$, a scan speed of $100 \mathrm{~nm} / \mathrm{min}$, and a $1-\mathrm{mm}$ path length cuvette at $25^{\circ} \mathrm{C}$. Five spectra were accumulated and averaged to increase the signal-to-noise ratio. Each spectrum was corrected by subtracting the lipid spectrum background, in the case where lipids were added to the solution. Lpcin $\mathrm{P}$ was dissolved to a $13.2 \mu M$ concentration in $10 \mathrm{mM} \mathrm{Na}_{2} \mathrm{HPO}_{4}(\mathrm{pH} \mathrm{7.4)}$ with $1 \%$ SDS, 90\% trifluoroethanol (TFE), or lipid vesicles of either pure DOPC or 80:20 (wt/wt) DOPC:DOPG in peptide-to-lipid ratios of 1:96 to 1:5 (1.27 $\mathrm{m} M$ LUV at a peptide-to-lipid ratio of 1:96). The mean residual ellipticity $(\theta)$ was calculated using the equation

$$
[\theta]=\frac{100 \theta M r}{c l N A},
$$

where $\theta$ is the CD signal in mdeg, $M_{r}$ is the molecular weight, $c$ is the peptide concentration in $\mathrm{mg} / \mathrm{mL}, l$ is the path length in $\mathrm{cm}$, and $N_{A}$ is the number of peptide bonds of the peptide (De Feijter et al., 1978). Finally, the $\%$ of $\alpha$-helicity was estimated by using the $\mathrm{k} 2 \mathrm{~d}$ algorithm on the online server for protein secondary structure analyses from CD spectroscopic data (Andrade et al., 1993; Whitmore and Wallace, 2008).

\section{Oriented Circular Dichroism}

Oriented CD measurements were performed as described (Wu et al., 1990; Chen et al., 2002). Various peptide-to-lipid ratios of Lpcin P and LUV of DOPC were prepared by adding peptide aliquots to preformed vesicles in $0.5 \mathrm{mM} \mathrm{Na} \mathrm{HPO}_{4}(\mathrm{pH}$ 7.4). The lipid concentration was kept at $5 \mathrm{mg} / \mathrm{mL}$ and $40 \mu \mathrm{L}$ of the peptide and LUV-containing sample were put onto a clean round quartz slide (cleaned repeatedly with both water and ethanol and allowed to air dry), resulting in deposition of $200 \mu \mathrm{g}$ of lipid film, containing 4.3 to 107.5 $\mu \mathrm{g}$ of Lpcin P, corresponding to ratios of 1:200 to 1:8, respectively. The quartz slides were left to air dry for 60 min and the lipid films were then rehydrated by vapor diffusion in a humidity chamber containing saturated solutions of $\mathrm{K}_{2} \mathrm{SO}_{4}$ or $\mathrm{MgCl}_{2}$ to obtain a vapor pressure equivalent to approximately $98 \%$ or approximately $33 \%$ relative humidity $(\mathbf{R H})$ at $25^{\circ} \mathrm{C}$ (Winston and Bates, 1960; Hunt et al., 1997). These hydration levels are denoted full or low hydration, respectively. The OCD spectra of alamethicin at $100 \%$ and approximately $98 \%$ RH are identical (Chen et al. 2002). After overnight equilibration, in turn, each quartz slide and a spacer were placed in a sample container as described by
Nielsen and Otzen (2010), together with $50 \mu \mathrm{L}$ of the same salt solution to maintain the desired RH. The OCD spectra of samples were recorded with the incident light perpendicular to the plane of the sample surface, using a Jasco J-810 spectropolarimeter (Jasco Spectroscopic Co.) at $25^{\circ} \mathrm{C}$. Measurements were made by scanning from 260 to $190 \mathrm{~nm}$, with a response time of $2 \mathrm{~s}, 0.2-\mathrm{nm}$ steps, a bandwidth of $2 \mathrm{~nm}$, and a scan speed of 100 $\mathrm{nm} / \mathrm{min}$. Seven spectra were accumulated for each of 8 different angles by turning the sample container in steps of $45^{\circ}$ and averaged to eliminate artifacts from linear dichroism and birefringence phenomena. The lack of deviations between spectra at different angles indicates that neither spectral artifacts in the quartz nor inhomogeneities in the sample contributed significantly to the final spectra. Each spectrum was further corrected by subtracting a background spectrum, containing only lipid. The precise amount of peptide within the beam of light could not be determined; therefore, all recorded spectra were normalized to an OCD value of -1 at 224 $\mathrm{nm}$.

\section{Calcein Release Assay}

Calcein dye leakage was monitored using a Tecan GENios Pro microplate reader (Tecan Group Ltd., Männedorf, Switzerland) in 96-well optical plates. Calcein vesicles were added to a final concentration of $3.8 \mu M$ to serial dilutions of Lpcin P, PP3, and PP3, respectively. All experiments were performed in triplicate. Fluorescence intensity changes were measured overnight with an excitation wavelength of $485 \mathrm{~nm}$ and detection of the emitted light at $520 \mathrm{~nm}$, with 2 $\mathrm{s}$ of autoshaking between each round of measurement. Baseline fluorescence $\left(F_{0}\right)$ was measured in wells with $10 \mathrm{mM} \mathrm{Na} \mathrm{HPO}_{4}$ (pH 7.4) and calcein vesicles. Correspondingly, the maximum possible calcein release $\left(F_{\max }\right)$ was measured in wells containing $10 \mathrm{mM} \mathrm{Na}_{2} \mathrm{HPO}_{4}(\mathrm{pH}$ 7.4), calcein vesicles, and Tween-20. The calcein release caused by Lpcin P and PP3 (full-length protein) was measured on the Tecan GENios Pro microplate reader. Bovine serum albumin and Novicidin were used as a negative and positive control, respectively. The relative amount of released calcein was calculated as follows:

$$
\text { dye leakage }=\frac{F-F_{0}}{F \max -F_{0}} \times 100 \% .
$$

\section{Antibacterial Assays}

The bacterial strains used in the antibacterial assays: Staph. aureus (USSA08), E. coli (USEC08), and Strep. 
thermophilus (AFI08) were all from our own collection. Serial dilutions of Lpcin P, Lpcin S, PP3, and Novicidin were made in PBS and a standard inoculum of $16-\mathrm{h}$ culture cells was added to a final concentration of $10^{5}$ $\mathrm{cfu} / \mathrm{mL}$. Final concentrations of peptide or protein were 0.2 to $90 \mu M$. Control tubes contained all of the components except the peptides and proteins. The tubes were incubated at $37^{\circ} \mathrm{C}$ for $1 \mathrm{~h}$, after which $25 \mu \mathrm{L}$ was placed on an agar plate as a drop. By tilting the plate, the drop spread evenly on top of the agar. The agar plates were incubated at $37^{\circ} \mathrm{C}$ for $18 \mathrm{~h}$ and then the number of colonies on the plates was counted. The drop inhibition assays were made in triplicate. Todd Hewitt broth and blood plates were used for Staph. aureus (USSA08) and E. coli (USEC08). The M17 broth and agar plates were used for Streptococcus thermophilus (AFI08).

\section{RESULTS AND DISCUSSION}

The Lpcin $\mathrm{P}$ was purified from trypsinated PP3 (Figure 1A). The Lpcin P (residues 110-135 of PP3) contains an additional 3 AA (Asn-Leu-Glu) in the Nterminal, compared with the synthetic Lpcin S peptide (residues 113-135; Campagna et al., 1998; Campagna et al., 2001, 2004),. However, the 3 AA are positioned within the sequence previously shown to form the amphipathic helix and no post-translational modifications are located in this region of PP3 (Bak et al., 2000).

To investigate the conformational properties of the amphipathic helix under conditions mimicking a membrane environment, Lpcin $\mathrm{P}$ was incubated together with either synthetic phospholipid vesicles, the anionic surfactant SDS, or the fluorinated alcohol TFE, and far-UV CD spectra were recorded. Furthermore OCD was performed to evaluate the orientation of helices within oriented multilayer membranes. To examine if Lpcin P could disrupt lipid bilayers, a calcein release assay was used. Finally the Lpcin P and PP3 were tested for antibacterial activity against Strep. thermophilus, E. coli, and Staph. aureus.

\section{Lpcin P Shows a-Helical Structure in Buffer and $\alpha$-Helicity Increases in Lipid Vesicles and Other Solvents}

Far-UV CD spectra of Lpcin P showed that the peptide adopts a conformation calculated to contain $22 \%$ $\alpha$-helical structure in aqueous solution (compare the 2 characteristic negative peaks at 222 and $208 \mathrm{~nm}$ as well as a positive peak at approximately $190 \mathrm{~nm}$; Figure 2 ). Interestingly, under the same conditions, Lpcin S showed random coil structure in aqueous solution (data not shown). This finding is in agreement with previous studies of Lpcin S structure (Campagna et al., 1998, 2001).

The Lpcin $\mathrm{P}$ dissolved in 1\% SDS ( $35 \mathrm{mM})$, which is well above the SDS concentration needed to form micelles (Mukerjee, 1967), retained the same basic $\alpha$-helical features as in the absence of SDS. However, a $>50 \%$ increase occurred in mean residue ellipticity, which translated into $83 \%$-helicity. The $90 \%$ TFE induced the highest level of helicity (99\%; Figure 2). Anionic detergents and organic solvents, such as SDS and TFE, are known to stabilize the helical conformation due to their ability to weaken the hydrophobic interactions within a polypeptide chain, and to strengthen the intramolecular hydrogen bonds between residues (Jirgensons, 1967; Roccatano et al., 2002; Otzen, 2010).

To mimic a membrane-like environment, CD spectra were also recorded in 2 different lipid vesicle solutions with a peptide-to-lipid ratio of 1:96. Far-UV CD spectra of Lpcin $\mathrm{P}$ were recorded in the presence of either electrically neutral (zwitterionic) DOPC vesicles or partly negatively charged 80:20 (wt/wt) DOPCDOPG. In the presence of lipid vesicles, an increase in $\alpha$-helical content of Lpcin P was observed compared with that in aqueous solution. In the presence of 80:20 (wt/wt) DOPC-DOPG, $72.9 \% \alpha$-helicity was observed, whereas only $57.7 \%$ - -helicity was observed in DOPC. An increased level of $\alpha$-helicity in the presence of anionic phospholipids is consistent with previous studies of Lpcin S (Campagna et al., 1999; Barzyk et al., 2009). $\alpha$-Helix formation upon interactions with partly negatively charged lipid surfaces have been observed before in other AMP such as Novicidin (Liu and Deber, 1997; Vad et al., 2010). The amphiphilic $\alpha$-helix structure is a common feature of AMP, such as the defensins, which constitute a main part of the innate immune system (Wilmes et al., 2011).

In contrast to Lpcin S, Lpcin $\mathrm{P}$ displayed a high degree of helical structure in the absence of detergents, organic solvents, or lipid vesicles. Moreover, the $\alpha$-helicity increased in the presence of lipids $[57.7$ and $72.9 \% \alpha$-helicity in the presence of $100 \%$ DOPC and 80:20 (wt/wt) DOPC:DOPG, respectively] and other solvents (83.2 and $98.7 \% \alpha$-helicity in the presence of $1 \%$ SDS and 90\% TFE, respectively). The reason for the difference between Lpcin $\mathrm{P}$ and Lpcin $\mathrm{S}$ may be assigned to the extra $3 \mathrm{~N}$-terminal AA in Lpcin P. It has previously been shown that the addition of a few AA in synthetic Lpcin can induce significant changes in its physical properties (Campagna et al. 2001). Apart from this, the only difference among the peptides is that Lpcin S is generated synthetically, whereas Lpcin $\mathrm{P}$ is generated by trypsin proteolysis of PP3 purified from milk. 


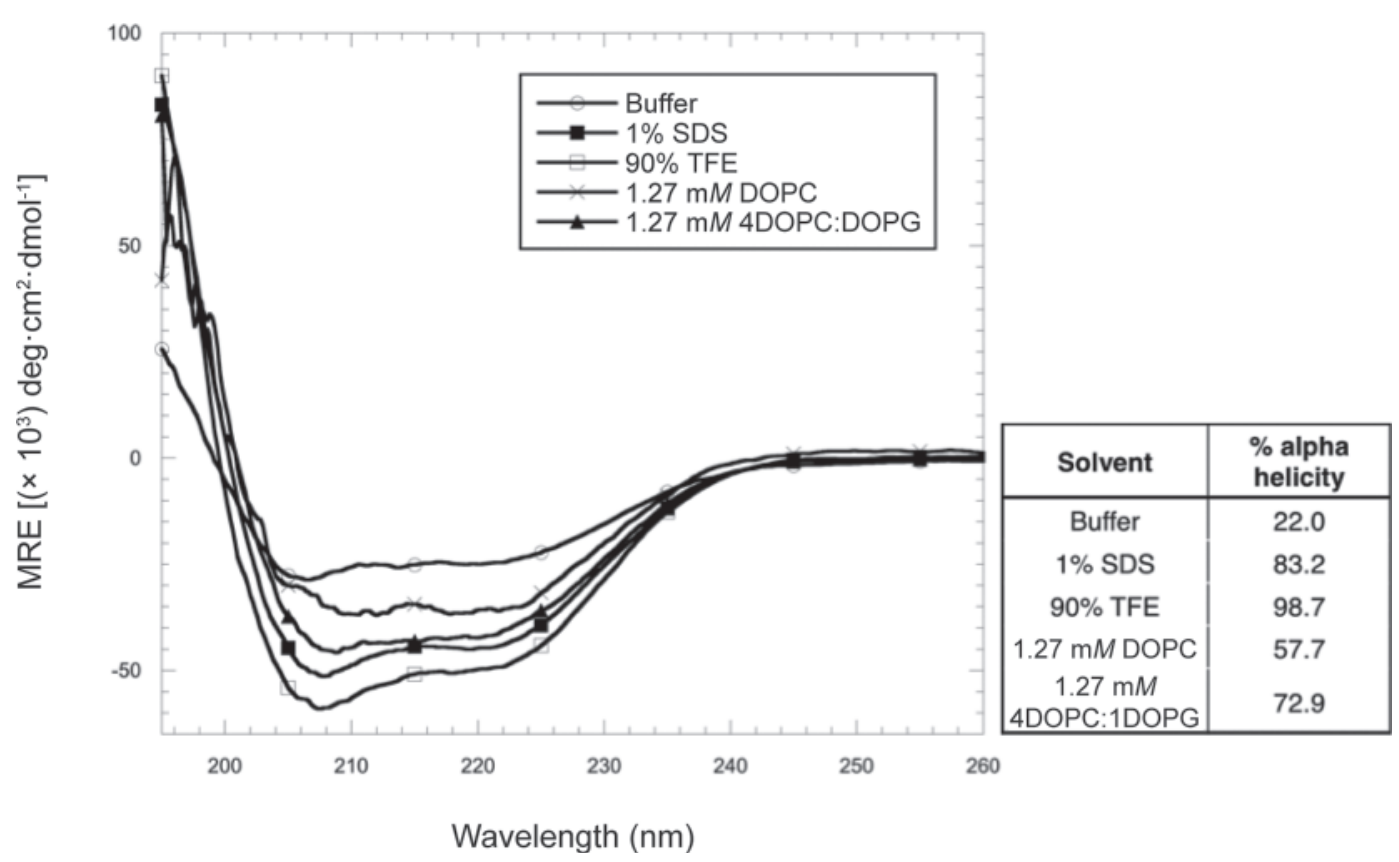

Figure 2. Circular dichroism (CD) spectra of the peptide (Lpcin P) covering the C-terminal 26 AA (residues 110 to 135 ), generated by in vitro trypsin proteolysis of native proteose peptone component 3, in mixtures of $10 \mathrm{~m} M \mathrm{Na}_{2} \mathrm{HPO}_{4}$ (pH 7.4), 1\% SDS, 90\% trifluoroethanol (TFE), $1 \mathrm{mg} / \mathrm{mL}$ of 1,2-dioleoylphosphatidylcholine (DOPC), or $1 \mathrm{mg} / \mathrm{mL} \mathrm{80:20} \mathrm{(wt/wt)} \mathrm{DOPC:1,2-dioleoylphosphatidylglycerol} \mathrm{(DOPG)} \mathrm{at}$ $25^{\circ} \mathrm{C}$. The percentage of $\alpha$-helix structure is given in the table. $\mathrm{MRE}=$ mean residual ellipticity.

\section{Lpcin P Is Oriented Parallel to the Membrane Plane}

Oriented CD spectra were recorded to probe the orientation of Lpcin $\mathrm{P}$ in the lipid bilayers. Figure 3A depicts the OCD spectra of fully hydrated Lpcin $\mathrm{P}$ in $\mathrm{DOPC}$ for a series of peptide-to-lipid ratios at $25^{\circ} \mathrm{C}$. The OCD spectra were normalized to the negative minimum at $224 \mathrm{~nm}$. The spectra of peptide-to-lipid ratios between 1:200 and 1:8 all displayed the 2 characteristic negative peaks at 222 and $208 \mathrm{~nm}$, and no difference in intensity at $208 \mathrm{~nm}$ was observed between the spectra and no red shift of the approximately 190-nm peak. This clearly suggests that the helices remain oriented parallel to the membrane plane and, thus, positioned on the surface, rather than being inserted into the membrane (Bak et al., 2000; Yang et al., 2001) even up to a peptide-to-lipid ratio of 1:8. The same features were seen in OCD spectra of Lpcin P with 80:20 (wt/ wt) DOPC:DOPG (data not shown). Likewise, OCD spectra of the dehydrated membranes with Lpcin $\mathrm{P}$ at a 1:200 to 1:8 peptide-to-lipid ratio did not change (data not shown). Lipid films were dehydrated using saturated $\mathrm{MgCl}_{2}$ salt solution, which caused the relative humidity to decrease from 98 to $33 \%$.

Solution CD spectra of Lpcin S and DOPG vesicles at peptide-to-lipid ratios ranging from 1:96 to 1:5 were recorded to determine whether any changes in secondary structure could affect the OCD spectra (Figure 3B).
The CD spectra (Figure 2 and Figure 3A) show that Lpcin $\mathrm{P}$ adopts a higher degree of $\alpha$-helicity in the presence of DOPG compared with when only electrically neutral lipids (DOPC) are present. However, no change occurred in mean residue ellipticity at both 208 and 222 $\mathrm{nm}$ for 100\% DOPC and 80:20 (wt/wt) DOPC:DOPG when we varied the peptide-to-lipid ratio from 1:96 to 1:5. These results suggest that Lpcin $\mathrm{P}$ does not form pores in membranes by the barrel-stave mechanism, as has been suggested for synthetic Lpcin S (Campagna et al., 2001).

\section{Lpcin P Permeabilizes Membranes More Efficiently Than PP3}

The membrane-perturbing activities of Lpcin $\mathrm{P}$ and full-length PP3 were evaluated by their ability to permeabilize LUV in the calcein-release assay. Calcein within the LUV is present at self-quenching concentrations (70 $\mathrm{m} M$ ) but upon permeabilization by, for example, an antimicrobial peptide, the fluorophore is released, leading to dilution and an increase in fluorescence emission. The Lpcin P, PP3, and the antimicrobial peptide Novicidin (positive control) all permeabilized pure DOPC and 80:20 (wt/wt) DOPC:DOPG vesicles, but to very different extents (Figure 4). Both types of vesicles showed instant release of calcein (within seconds) when incubated with Lpcin P and reached a release of $50 \%$ 

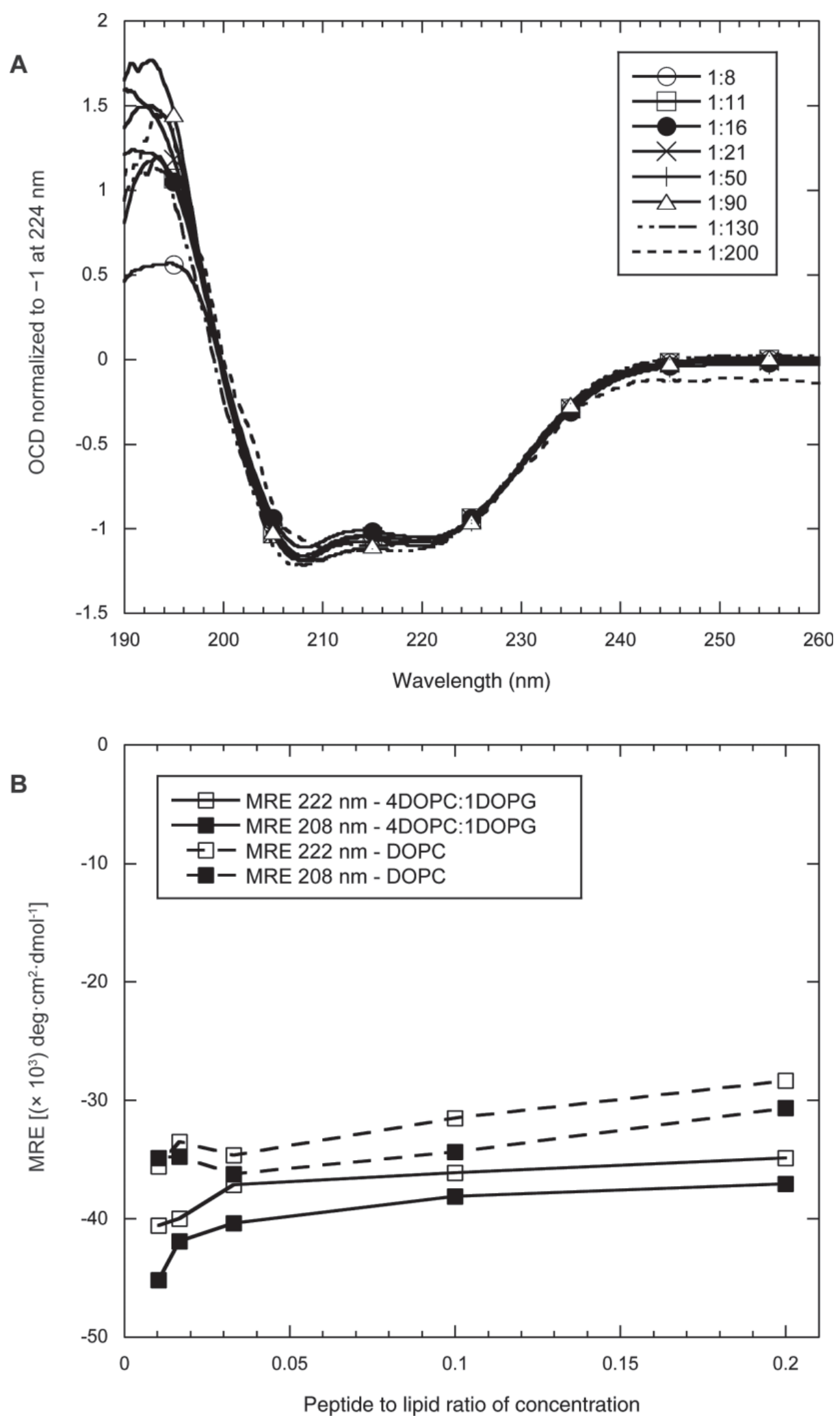

Figure 3. Oriented circular dichroism (OCD) spectra of the peptide (Lpcin P) covering the C-terminal 26 AA (residues 110 to 135), generated by in vitro trypsin proteolysis of native proteose peptone component 3. A) OCD spectra in 100\% 1,2-dioleoylphosphatidylcholine (DOPC) large unilamellar vesicles (LUV) at different peptide:lipid ratios. The spectra were normalized to -1 at $224 \mathrm{~nm}$. B) Solution circular dichroism (CD) spectra of Lpcin P in 100\% DOPC or 80:20 (wt/wt) DOPC:1,2-dioleoylphosphatidylglycerol (DOPG) LUV at peptide-to-lipid ratios of 1:96 to $1: 5$. $\mathrm{MRE}=$ mean residual ellipticity. 

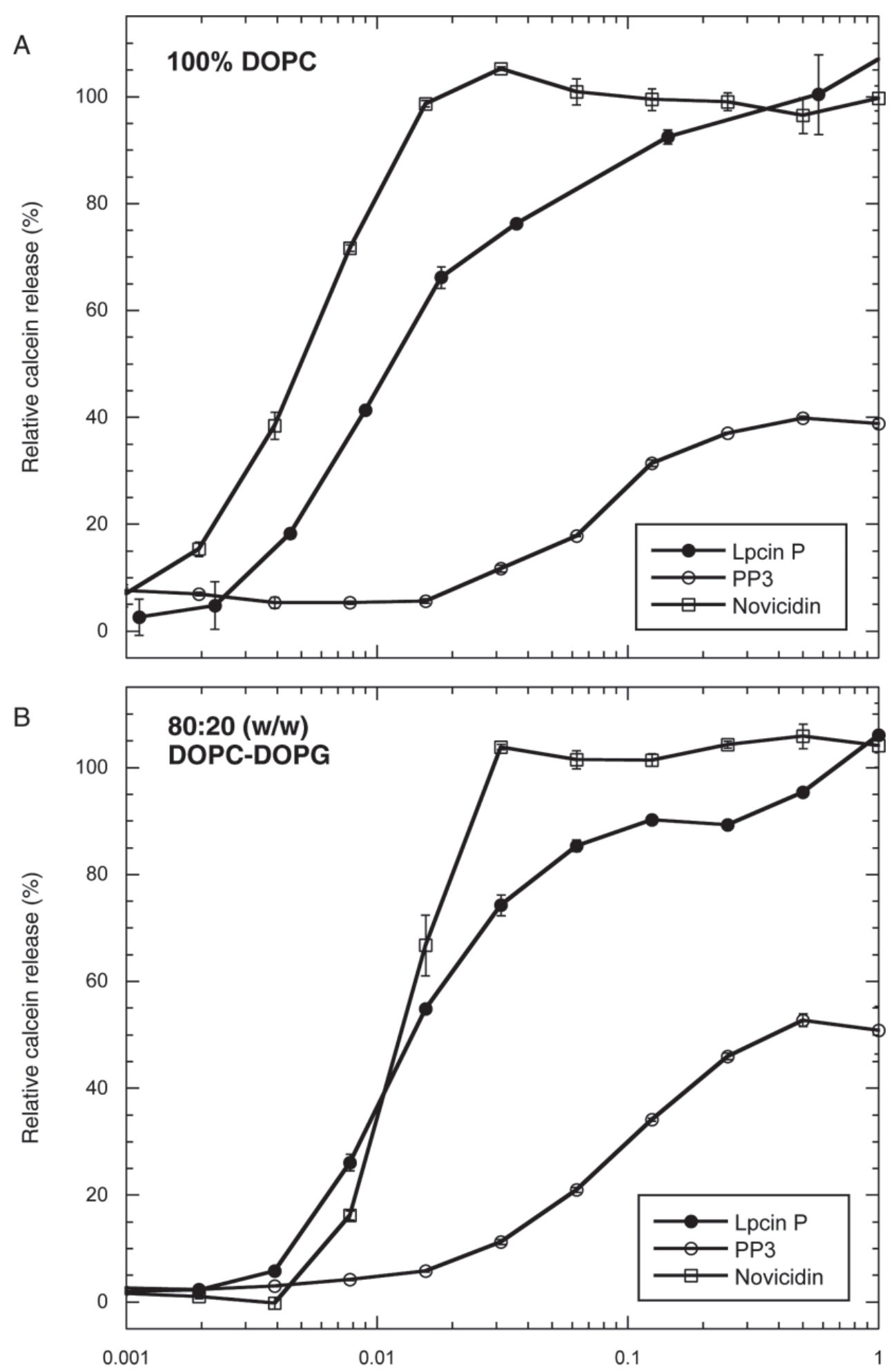

Peptide to lipid ratio of concentration

Figure 4. Calcein dye release from 100\% 1,2-dioleoylphosphatidylcholine (DOPC; A) or 80:20 (wt/wt) DOPC:1,2-dioleoylphosphatidylglycerol (DOPG; B) large unilamellar vesicles (LUV), measured for 25 min. The normalized maximum fluorescence was plotted as a function of the molar protein:lipid ratio. The permeabilization activity of the peptide (Lpcin P) covering the C-terminal 26 AA (residues 110 to 135), generated by in vitro trypsin proteolysis of native proteose peptone component 3 (PP3); PP3; and Novicidin was tested. Standard deviations are shown; however, in several of the data points they are so small, that they are not visible. 


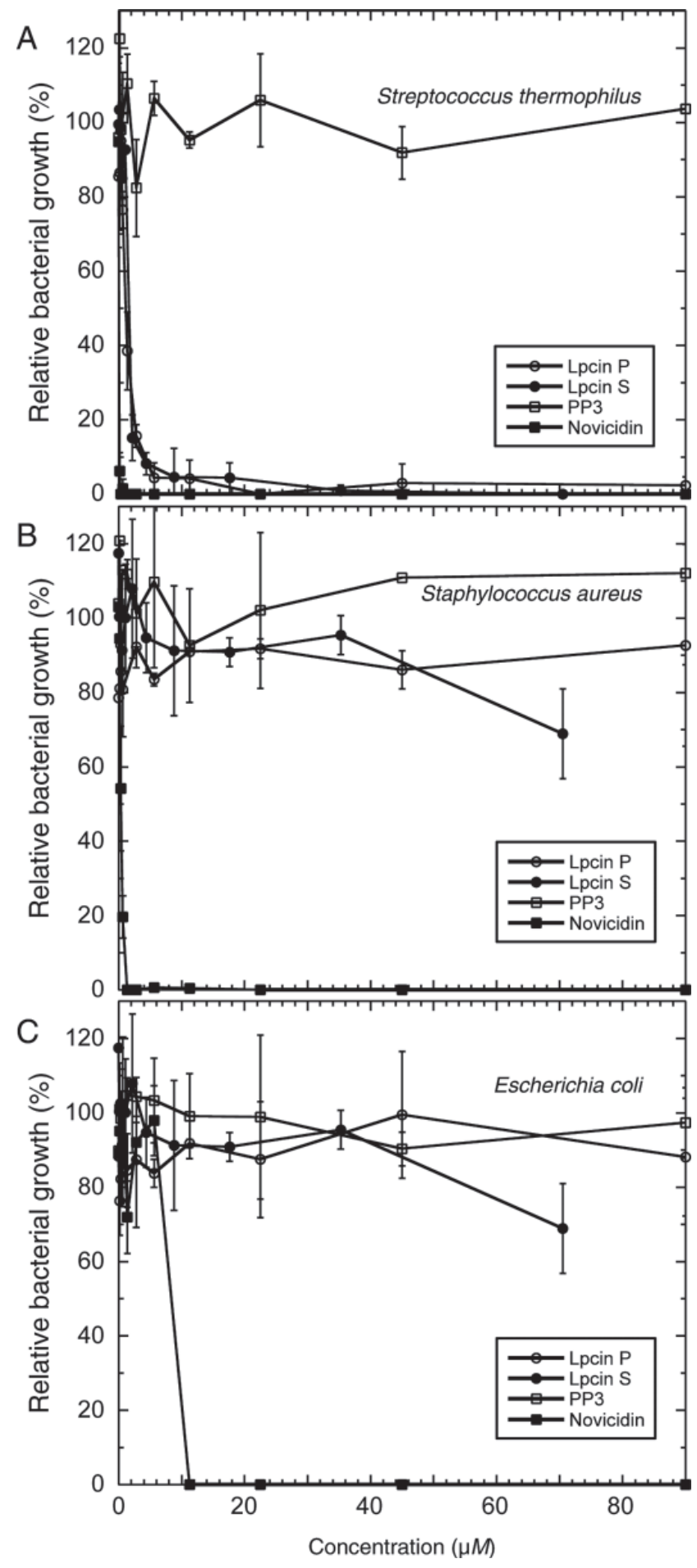

Figure 5. Antibacterial activity of the peptide (Lpcin P) covering the C-terminal $26 \mathrm{AA}$ (residues 110 to 135), generated by in vitro trypsin proteolysis of native proteose peptone component 3 (PP3); lactophoricin (Lpcin S); PP3; and Novicidin were tested against Streptococcus thermophilus (AFI08; A), Escherichia coli (USEC08; B), and Staphylococcus aureus (USSA08; C). Standard suspensions of bacteria $\left(10^{5} \mathrm{cfu} / \mathrm{mL}\right)$ were incubated in serial dilutions of the peptides/ protein and were spread out on an agar plate. Colonies on the plates were counted after $18 \mathrm{~h}$. Experiments were done in triplicate and standard deviations are indicated. at a peptide-to-lipid ratio of 1:100, comparable to the highly membrane-active Novicidin (Figure 4). The release caused by PP3 was much slower (on the scale of minutes) and reached a plateau of only approximately $50 \%$. This illustrates that PP3 needs to be activated by proteolytic cleavage to efficiently permeabilize lipid bilayers.

\section{Antibacterial Activity of Lpcin P}

Previous studies have shown Lpcin S to display antibacterial activity (Campagna et al., 2004). To extend the studies of the permeabilizing ability of Lpcin $\mathrm{P}$ and to compare the potential antibacterial activity with that reported for Lpcin S, we measured the bacterial growth of representative bacterial strains in vitro, in the presence of serial dilutions of Lpcin $\mathrm{P}$ and Lpcin $\mathrm{S}$ (Figure 5). The Lpcin $\mathrm{P}$ and Lpcin S did not inhibit the growth of the gram-positive Staph. aureus and the gram-negative E. coli (Figure 5B,C). However, as seen for Lpcin S (Campagna et al., 2004), a marked reduction in growth of Strep. thermophilus was observed, when treated with either Lpcin P or Lpcin S (Figure $5 \mathrm{~A})$. We observed $100 \%$ bacterial growth inhibition of Strep. thermophilus at $22 \mu M$ Lpcin P concentration. The corresponding concentration of Lpcin S showed an inhibition of $95 \%$. $\mathrm{IC}_{50}$ was approximately $1.1 \mu \mathrm{M}$ and approximately $1.7 \mu M$ for Lpcin P and Lpcin S, respectively, which is well below the reported concentrations of PP3 in bovine milk ( $\sim 16 \mu M$; Paquet et al., 1985). The PP3 full-length protein showed no antibacterial effect against any of the analyzed bacterial strains. Hence, the present work shows that a proteolytically generated peptide from PP3 possesses antibacterial properties and is as efficient as the previously studied synthetic peptide.

The effect on Strep. thermophilus is very interesting from a dairy perspective, as these bacteria are considered to be very beneficial in fermented dairy products (Rhimi et al., 2010). In the current study, only a few representative bacterial strains have been tested and whether the peptides possess antibacterial activities against other bacterial strains remains to be tested.

In summary, Lpcin $\mathrm{P}$ adopts an $\alpha$-helical structure in solution and the helix propensity increases when dissolved in anionic surfactant, organic solvent, or in the presence of lipid vesicles. According to the OCD spectra, Lpcin $\mathrm{P}$ was oriented in plane with the membrane surface, but was found to be efficient in the permeabilization of lipid vesicles. The results indicate that permeabilization by Lpcin $\mathrm{P}$ uses a mechanism other than the conventional pore-forming barrel-stave mechanism (Yang et al., 2001). Also, Lpcin P displayed bactericidal activity against the nonpathogenic gram- 
positive Strep. thermophilus and 50\% inhibition at a Lpcin P concentration corresponding to less than onetenth of the PP3 concentration in bovine milk. The results showed that PP3 has to be proteolytically processed to release peptides that are able to permeabilize membranes and act as antibacterial agents.

\section{ACKNOWLEDGMENTS}

Thanks to Nikolaj Lorentzen (Department of Molecular Biology and Genetics, Aarhus University, Aarhus, Denmark) for assistance with the use of the Tecan GENios Pro microplate reader (Tecan Group Ltd., Männedorf, Switzerland) and Lise Møller Fogh (Department of Molecular Biology and Genetics, Aarhus University) for invaluable technical help whenever needed. The project was financed by the Interdisciplinary Nanoscience Center (iNANO, Aarhus University, Aarhus, Denmark) as well as the Milk Protein Research Consortium (Aarhus, Denmark).

\section{REFERENCES}

Andrade, M. A., P. Chacón, J. J. Merelo, and F. Morán. 1993. Evaluation of secondary structure of proteins from UV circular dichroism spectra using an unsupervised learning neural network. Protein Eng. 6:383-390.

Bak, M., M. D. Sørensen, E. S. Sørensen, L. K. Rasmussen, O. W. Sørensen, T. E. Petersen, and N. C. Nielsen. 2000. The structure of the membrane-binding $38 \mathrm{C}$-terminal residues from bovine PP3 determined by liquid- and solid-state NMR spectroscopy. Eur. J. Biochem. 267:188-199.

Barzyk, W., S. Campagna, K. Więcław, B. Korchowiec, and E. Rogalska. 2009. The affinity of two antimicrobial peptides derived from bovine milk proteins for model lipid membranes. Colloids Surf. A 343:104-110.

Beg, O. U., H. von Bahr-Lindström, Z. H. Zaidi, and H. Jörnvall. 1987. Characterization of a heterogeneous camel milk whey non-casein protein. FEBS Lett. 216:270-274.

Campagna, S., P. Cosette, G. Molle, and J.-L. Gaillard. 2001. Evidence for membrane affinity of the C-terminal domain of bovine milk PP3 component. Biochim. Biophys. Acta 1513:217-222.

Campagna, S., A. G. Mathot, Y. Fleury, J.-M. Girardet, and J.-L. Gaillard. 2004. Antibacterial activity of lactophoricin, a synthetic 23-residues peptide derived from the sequence of bovine milk component-3 of proteose peptone. J. Dairy Sci. 87:1621-1626.

Campagna, S., N. Van Mau, F. Heitz, G. Humbert, and J.-L. Gaillard. 1999. Specific interaction between anionic phospholipids and milk bovine component PP3 and its 119-135 C-terminal fragment. Colloids Surf. B 13:299-309.

Campagna, S., B. Vitoux, G. Humbert, J. M. Girardet, G. Linden, T. Haertle, and J. L. Gaillard. 1998. Conformational studies of a synthetic peptide from the putative lipid-binding domain of bovine milk component PP3. J. Dairy Sci. 81:3139-3148.

Cantisani, A., L. Napolitano, M. G. Giuffrida, and A. Conti. 1990. Direct identification and characterization of llama (Lama glama L.) whey proteins by microsequencing after Western blotting. J. Biochem. Biophys. Methods 21:227-236.

Chen, F.-Y., M.-T. Lee, and H. W. Huang. 2002. Sigmoidal concentration dependence of antimicrobial peptide activities: A case study on alamethicin. Biophys. J. 82:908-914.

Christensen, B., T. E. Petersen, and E. S. Sørensen. 2008. Post-translational modification and proteolytic processing of urinary osteopontin. Biochem. J. 411:53-61.
De Feijter, J. A., J. Benjamins, and F. A. Veer. 1978. Ellipsometry as a tool to study the adsorption behavior of synthetic and biopolymers at the air-water interface. Biopolymers 17:1759-1772.

Dowbenko, D., A. Kikuta, C. Fennie, N. Gillett, and L. A. Lasky. 1993a. Glycosylation-dependent cell adhesion molecule 1 (GlyCAM 1) mucin is expressed by lactating mammary gland epithelial cells and is present in milk. J. Clin. Invest. 92:952-960.

Dowbenko, D., S. R. Watson, and L. A. Lasky. 1993b. Cloning of a rat homologue of mouse GlyCAM 1 reveals conservation of structural domains. J. Biol. Chem. 268:14399-14403.

Expósito, I. L., and I. Recio. 2006. Antibacterial activity of peptides and folding variants from milk proteins. Int. Dairy J. 16:12941305.

Graham, J. M., and J. A. Higgins. 1997. Membrane Analysis. Taylor \& Francis Inc, New York, NY.

Groenen, M. A. M., R. J. M. Dijkhof, and J. J. van der Poel. 1995. Characterization of a GlyCAM1-like gene (glycosylation-dependent cell adhesion molecule 1) which is highly and specifically expressed in the lactating bovine mammary gland. Gene 158:189-195.

Hunt, J. F., P. Rath, K. J. Rothschild, and D. M. Engelman. 1997. Spontaneous, $\mathrm{pH}$-dependent membrane insertion of a transbilayer alpha-helix. Biochemistry 36:15177-15192.

Jirgensons, B. 1967. Effects of n-propyl alcohol and detergents on the optical rotatory dispersion of alpha-chymotrypsinogen, betacasein, histone fraction F1, and soybean trypsin inhibitor. J. Biol. Chem. 242:912-918.

Johnsen, L. B., E. S. Sørensen, T. E. Petersen, and L. Berglund. 1995. Characterization of a bovine mammary gland PP3 cDNA reveals homology with mouse and rat adhesion molecule GlyCAM-1. Biochim. Biophys. Acta 1260:116-118.

Kanoh, N., C. F. Dai, T. Tanaka, D. Izawa, Y. F. Li, H. Kawashima, and M. Miyasaka. 1999. Constitutive expression of GlyCAM-1 core protein in the rat cochlea. Cell Adhes. Commun. 7:259-266.

Lasky, L. A., M. S. Singer, D. Dowbenko, Y. Imai, W. J. Henzel, C. Grimley, C. Fennie, N. Gillett, S. R. Watson, and S. D. Rosen. 1992. An endothelial ligand for L-selectin is a novel mucin-like molecule. Cell 69:927-938.

Lister, I. M. B., L. K. Rasmussen, L. B. Johnsen, L. Møller, T. E. Petersen, and E. S. Sørensen. 1998. The primary structure of caprine PP3: Amino acid sequence, phosphorylation, and glycosylation of component PP3 from the proteose-peptone fraction of caprine milk. J. Dairy Sci. 81:2111-2115.

Liu, L.-P., and C. M. Deber. 1997. Anionic phospholipids modulate peptide insertion into membranes. Biochemistry 36:5476-5482.

Matsuzaki, K., O. Murase, N. Fujii, and K. Miyajima. 1996. An antimicrobial peptide, magainin 2, induced rapid flip-flop of phospholipids coupled with pore formation and peptide translocation. Biochemistry 35:11361-11368.

Mukerjee, P. 1967. The nature of the association equilibria and hydrophobic bonding in aqueous solutions of association colloids. Adv Colloid Interface Sci. 1:241-275.

Nielsen, S. B., and D. E. Otzen. 2010. Impact of the antimicrobial peptide Novicidin on membrane structure and integrity. J. Colloid Interface Sci. 345:248-256.

Oren, Z., and Y. Shai. 1998. Mode of action of linear amphipathic $\alpha$-helical antimicrobial peptides. Biopolymers 47:451-463.

Otzen, D. E. 2010. Amyloid formation in surfactants and alcohols: Membrane mimetics or structural switchers? Curr. Protein Pept. Sci. 11:355-371.

Paquet, D., Y. Nejjar, and C. Alais. 1985. Electrophoretic and chromatographic behavior of the proteose-peptone fraction of cows milk. Milchwissenschaft 40:200-203.

Pedersen, L. R. L., S. B. Nielsen, J. G. Hansted, T. E. Petersen, D. E. Otzen, and E. S. Sørensen. 2012. PP3 forms stable tetrameric structures through hydrophobic interactions via the C-terminal amphipathic helix and undergoes reversible thermal dissociation and denaturation. FEBS J. 279:336-347.

Rasmussen, L. K., L. B. Johnsen, T. E. Petersen, and E. S. Sørensen. 2002. Human GlyCAM-1 mRNA is expressed in the mammary gland as splicing variants and encodes various aberrant truncated proteins. Immunol. Lett. 83:73-75. 
Rhimi, M., A. Boisson, M. Dejob, S. Boudebouze, E. Maguin, R. Haser, and N. Aghajari. 2010. Efficient bioconversion of lactose in milk and whey: Immobilization and biochemical characterization of a beta-galactosidase from the dairy Streptococcus thermophilus LMD9 strain. Res. Microbiol. 161:515-525.

Roccatano, D., G. Colombo, M. Fioroni, and A. E. Mark. 2002. Mechanism by which 2,2,2-trifluoroethanol/water mixtures stabilize secondary-structure formation in peptides: A molecular dynamics study. Proc. Natl. Acad. Sci. USA 99:12179-12184.

Sansom, M. S. 1991. The biophysics of peptide models of ion channels. Prog. Biophys. Mol. Biol. 55:139-235.

Sørensen, E. S., and T. E. Petersen. 1993a. Phosphorylation, glycosylation and amino acid sequence of component PP3 from the proteose peptone fraction of bovine milk. J. Dairy Res. 60:535-542.

Sørensen, E. S., and T. E. Petersen. 1993b. Purification and characterization of three proteins isolated from the proteose peptone fraction of bovine milk. J. Dairy Res. 60:189-197.

Sørensen, E. S., L. K. Rasmussen, L. Møller, and T. E. Petersen. 1997. The localization and multimeric nature of component PP3 in bovine milk: Purification and characterization of PP3 from caprine and ovine milks. J. Dairy Sci. 80:3176-3181.

Spencer, T. E., F. F. Bartol, F. W. Bazer, G. A. Johnson, and M. M. Joyce. 1999. Identification and characterization of glycosylationdependent cell adhesion molecule 1-like protein expression in the ovine uterus. Biol. Reprod. 60:241-250.
Vad, B., L. A. Thomsen, K. Bertelsen, M. Franzmann, J. M. Pedersen, S. B. Nielsen, T. Vosegaard, Z. Valnickova, T. Skrydstrup, J. J. Enghild, R. Wimmer, N. C. Nielsen, and D. E. Otzen. 2010. Divorcing folding from function: How acylation affects the membrane-perturbing properties of an antimicrobial peptide. Biochim. Biophys. Acta 1804:806-820.

Whitmore, L., and B. A. Wallace. 2008. Protein secondary structure analyses from circular dichroism spectroscopy: Methods and reference databases. Biopolymers 89:392-400.

Wilmes, M., B. P. A. Cammue, H.-G. Sahl, and K. Thevissen. 2011. Antibiotic activities of host defense peptides: More to it than lipid bilayer perturbation. Nat. Prod. Rep. 28:1350-1358.

Winston, P. W., and D. H. Bates. 1960. Saturated solutions for the control of humidity in biological research. Ecology 41:232-237.

Wu, Y., H. W. Huang, and G. A. Olah. 1990. Method of oriented circular dichroism. Biophys. J. 57:797-806.

Yang, L., T. A. Harroun, T. M. Weiss, L. Ding, and H. W. Huang. 2001. Barrel-stave model or toroidal model? A case study on melittin pores. Biophys. J. 81:1475-1485.

Zimecki, M., and M. L. Kruzel. 2007. Milk-derived proteins and peptides of potential therapeutic and nutritive value. J. Exp. Ther. Oncol. 6:89-106. 